\title{
PROPOSAL OF MODEL FOR EFFECTIVE MANAGEMENT OF COOPERATION ACTIVITIES IN SLOVAK COMPANIES
}

\begin{abstract}
Aim of this article is to offer a proposal for effective planning and organization of cooperation activities in a company, based on a comprehensive analysis of scientific literature and performed empirical research in Slovak republic. The article thus provides a tool for company managers for managing their cooperation activities. Use of this tool is meant to help minimize occurrence of conflict situations and to support smooth progress of cooperation activities from the organizational and planning perspective.
\end{abstract}

Keywords: Cooperation, cooperation activities, cooperation management, planning, organization.

\section{Introduction}

The topic of managing cooperation activities is currently highly up-to-date. In present, cooperation as such represents for a company an important tool for increasing its competitiveness. The topic of managing cooperation activities is highly up-to- date in Slovak enterprises. Managers in Slovak companies strive to build in their enterprises a functioning cooperation process, which would help with establishing of successful partnerships and cooperations. In order for this initiative to be successful, it is necessary to apply elements of process management and to create an environment that would support establishing of partnerships, enable communication and efficient work with information related to cooperations. In this respect managers may find useful the model that we propose in this article for effective management of cooperation activities in a company.

\section{Objective and methodology}

The purpose of the article is to offer, in a comprehensible form, a coherent overview of managing cooperation activities in a company. This includes a methodology of planning and organizing company cooperation activities, which is based on a detailed mapping of theoretical and practical knowledge in the area of cooperation management and a performed research of the level at which it is used in Slovak enterprises.
In order to address the points in question, as set by this article, it was necessary to use several methods, depending on and fitting to the character of the individual parts of the solution. In order to accumulate necessary data, we used the method of document analysis (for analysis of current as well as historical data about the topic), a questionnaire method and a method of semi-structured interview (gathering data in an empirical research) and a method of observation (used during visits of selected companies).

For processing the data, we mainly used a method of quantitative evaluation (statistical methods and tools were applied) and a method of comparison (for comparing data gathered by empirical research and data from the analysis of secondary information sources).

The performed research focused on medium and large enterprises active in the Slovak Republic. The actual respondents were company managers on the mid to top management level within the managerial hierarchy of companies. In total, 221 respondents took part in the research focused on diagnostics of the level of use of cooperation management.

Research included companies active in multiple sectors of the Slovak economy. Companies included were categorized by the Statistical Office of the Slovak Republic as medium or large enterprises. Size of the sample was 345 respondents, with the required $95 \%$ interval of reliability and the maximum allowable error of $5 \%$. Since 221 respondents actually took part in the research, the maximum allowable error reached 6.37\%. Data was gathered exclusively via personal interview.

\footnotetext{
* Josef Vodak, Jakub Soviar, Viliam Lendel, Michal Varmus

Department of Management Theories, Faculty of Management Science and Informatics, University of Zilina, Slovakia

E-mail: josef.vodak@fri.uniza.sk
} 
The following methods were used for approaching and solving the research goals: induction, deduction, synthesis, abstraction and model building.

\section{The current state of dealing with the issue}

Scientific literature offers several theories that try to explain to managers how they could manage cooperation activities more efficiently and what factors influence the outcomes. Even though these theories look at the management of cooperation activities from various points of view, they all mention the need to create a complex illustration of company's cooperation activities. However, this effort often leads to excessive complexity and in the end may appear even confusing, thus failing to properly support the decision making processes in a company. It is often the case that the realized cooperation initiatives of a company fail to produce the expected outcomes.
Several authors ([1], [2], [3], [4] and [5]) point out that even though there is ongoing research in various areas of management of cooperation activities, the results are still not consistent. Creation of a unified view on the management of cooperation activities is largely blocked by the following factors:

- Cooperation management stems from several scientific branches (social sciences, economics, management, psychology...) and continues to interact with them.

Research in cooperation management is oriented towards various industries and markets that have specific characteristics.

- Theoretical and practical researchers are mainly interested in different types and forms of cooperations.

Even companies sometimes misinterpret the term cooperation management and the management of cooperation activities. While these companies emphasize the need to create new cooperations, many of them lack functional cooperation process that would

Summary of the contributions of individual approaches to managing company cooperation activities

Table 1

\begin{tabular}{|c|c|c|}
\hline Author(s) & Emphasis & Contribution \\
\hline Sahut a Peris-Ortiz [6] & Role of innovations in planning cooperation activities & $\begin{array}{l}\text { Basis = favourable environment for entrepreneurship } \\
\text { and innovations }\end{array}$ \\
\hline Ritala a Sainio [7] & $\begin{array}{l}\text { Determination and close collaboration between cooperating } \\
\text { parties }\end{array}$ & Application of the business model \\
\hline $\begin{array}{l}\text { Mutak [8], } \\
\text { Kultti [9] }\end{array}$ & Creation of cooperation networks & Application to the area of innovation of services \\
\hline Felzensztein et al. [10] & $\begin{array}{l}\text { Portfolio of the areas of collaboration and its gradual } \\
\text { expansion }\end{array}$ & Application to marketing activities and innovations \\
\hline Weck and Ivanova [11] & Trust between cooperating parties & $\begin{array}{l}\text { Gradual adaptation of business cultures of partner } \\
\text { organizations }\end{array}$ \\
\hline Wicks et al. [12] & Company performance & Cooperation process based on trust \\
\hline Fawcett et al. [13] & Correct understanding of trust & Dynamics of trust building in cooperation \\
\hline Monczka et al. [14] & Information background of cooperation processes & Quality of information and their sharing \\
\hline Jassawalla a Sashittal [15] & Organizational factors & Organizational structure that supports cooperation \\
\hline Schmoltzi a Wallenburg [16] & $\begin{array}{l}\text { Organizational and strategic complexity in building } \\
\text { cooperation management }\end{array}$ & Efficient planning of cooperation activities \\
\hline
\end{tabular}

Key elements of the management of cooperation activities

\begin{tabular}{|l|l|}
\hline Key element & Attributes \\
\hline Innovations & $\begin{array}{l}\text { A suitable environment should be established in a company that would support entrepreneurship and innovations, } \\
\text { characterized by determination and close collaboration between the cooperating parties. }\end{array}$ \\
\hline Trust & $\begin{array}{l}\text { This aspect is an important part of strategic decision making. Managers who use optimal trust in the relations with } \\
\text { the involved parties improve performance of the company. For this reason it is necessary to correctly understand } \\
\text { the character of trust and the dynamics of building trust within cooperation, and to pursue gradual adaption of the } \\
\text { business cultures of the cooperation partners. }\end{array}$ \\
\hline Organizational factors & $\begin{array}{l}\text { It is necessary to ensure the quality of information in the company, as well as its sharing for the needs of managerial } \\
\text { decision making. Effective work with information within a collaboration can help prevent conflicts and aid with } \\
\text { solving complex cooperation tasks. }\end{array}$ \\
\hline This aspect involves change of organizational structures to support cooperation, interest and support from top \\
management of the partners, openness to changes while maintaining mutual goals of the partner companies.
\end{tabular}


generate new partnerships. We noticed that in some companies there is a significant effort to build a functional cooperation. However, in many cases the cooperation does not bring the expected benefits (not only the financial ones), particularly because it does not have clear rules, metrics and methodology of evaluation, limited communication and cooperation between the sections of the company (logistics, manufacturing, marketing, research and development...) in relation to cooperations. Managers are often not familiar with the methodical toolbox for effective management of cooperation activities in a company.

The listed problems are interconnected and affect each other. It is therefore necessary to deal with them one by one. The first step is to analyze current theoretical models related to cooperation (Table 1) and to identify key elements of the management of cooperation activities (Table 2). The second step is to create complex model of efficient management of cooperation activities.

\section{Situation in Slovak enterprises - results of the empirical research}

Between September 2012 and February 2013 we conducted a research, with the primary goal to gather and interpret information about the level of use of cooperations in the environment of Slovak enterprises. The main goal of the research was to identify the key aspects of efficient management and functioning of cooperations, related issues, degree of satisfaction of companies within cooperation and the opportunities for improvement of already functioning cooperations. Data that was gathered provided complete picture about readiness of Slovak enterprises to use (implement) cooperation management. In total, 273 managers of small, medium and large enterprises took part in the research, from companies active in the Slovak Republic. Data from the respondents was gathered via personal interviews.

It could be considered positive that almost half of the respondents $(47.62 \%)$ plans in the near future (within one year) to establish a more intense cooperation with a company or an organization. When selecting partners for cooperation, companies make decisions based on the following factors: costs (8.12), insolvency (8.03), market position (7.25), profitability (7.18) and certificates (7.05). In contrast, the lowest importance was assigned to the factors such as the legal form (4.16) and company seat.

The main challenges and problems that were listed by respondents to occur in the process of cooperating with companies and organizations were mainly insufficient adherence to the agreed contractual terms ( $58.39 \%)$, financially demanding (35.04\%), distortion of information (34.41\%), low effectiveness of cooperation (29.56\%), unwillingness to provide internal information by a cooperating company, i.e. concerns about providing internal information to a company (28.83\%).

\section{Proposal of Model for Effective Management of Cooperation Activities in a Company}

Management of cooperation activities in a company is a real challenge faced by company managers. A number of elements play a role in establishing the management of cooperation activities, including theoretical concepts, modeled solutions and practical applications. Probably the most significant challenge is the lack of unified, complex, comprehensive yet understandable and clear model for management of cooperation activities in a company. Based on the results of the performed research we can conclude that at present many companies try to manage their cooperation activities and processes intuitively. Oftentimes they face multiple challenges while doing this, which arise mainly from the lack of readiness of a company to manage cooperation activities. During the interviews with representatives of companies that we conducted during the realized research, we identified the need for complex and at the same time clear and understandable model for the management of cooperation activities in a company. Such model would be very helpful to the managers.

In relation to the viewpoints of other authors who are working on models for management of cooperation activities and after thorough analysis of these approaches we proposed a model for management of cooperation activities in a company (Fig. 1).

The proposed model is related to the existence of a competitive environment as well as a cooperative environment. Organizations that are active in the competitive environment generally have an objective to remain competitive and to achieve their goals through effective processes. This objective creates the initial need. Organizations that are active in the competitive environment often have common goals as well as problems. In case a reciprocity of a coordinated approach is sufficiently attractive, organizations may agree on a cooperative solution. Cooperative solution starts with the process of facilitation, i.e. facilitation of a cooperation. The goal of this process is to establish a real cooperation. The result of the process of facilitation is a mutual agreement. In case the agreement is not reached, organizations continue to be active as mutual competitors. In case the agreement is reached, organizations start to act in the mutual cooperative environment. This environment is made of individual subjects for the purpose of achieving set goals. This environment is cooperative only towards the participating entities, while it is competitive towards other subjects.

Facilitation of a cooperation and management of a cooperation are processes that are directly influenced by the basic company processes - functions of management (decision making, organization, leadership, planning, and control). These functions are ongoing and determine effectiveness of these processes.

A key element in the model is feedback. It makes it possible to overcome arising problems in the individual phases of the cooperative process. The model also takes into account the element of learning, which contributes to continuous improvements within 
cooperation. Thus, organizations are able to learn based on the ongoing cooperative activities and are able to improve the way they manage these activities.

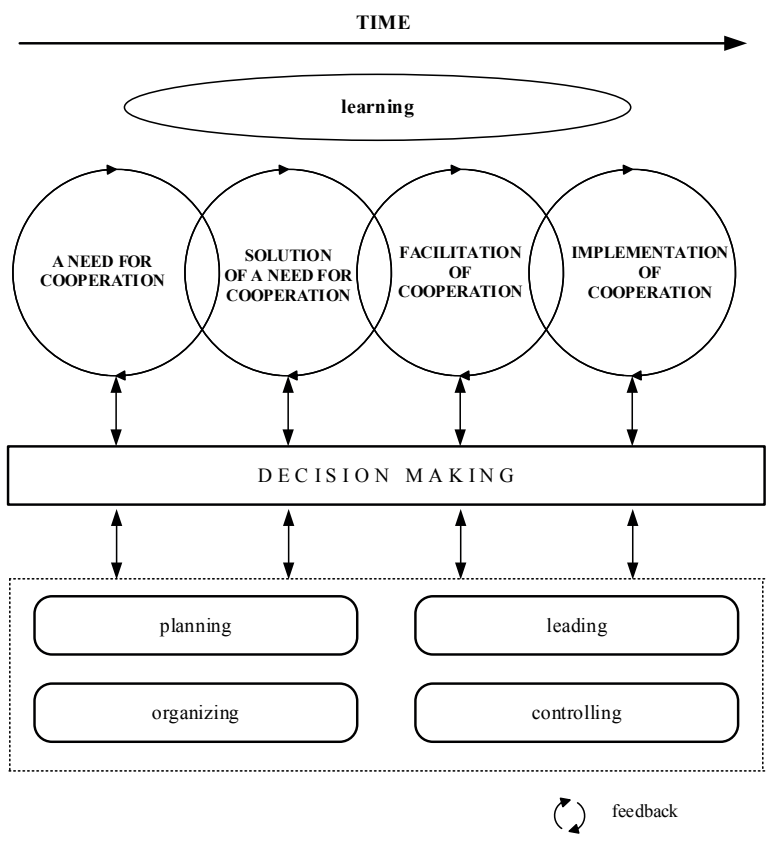

Fig. 1 Model for Effective Management of Cooperation Activities in a Company

Source: Own elaboration

\section{Effective Planning of Cooperation Activities in a Company}

Existence and justifiability of cooperation management is strongly influenced by the dynamic development of the market environment. For this reason planning represents a crucial part of all important processes here. Planning is ongoing on all levels of the goals - long-term (strategic goals, ca. 3 - 5 years), mid-term (tactical goals, ca. 1 - 3 years) as well as short-term (operational goals, ca. less than 1 year) (see [17]). In case of the planning within already existing cooperation connection, this is in the theoretical sense the case of standard methods. Specific situations arise in two cases:

- Planning as part of facilitation: Start and establishment of cooperation is a separate and specialized managerial process called labelled facilitation. Here is planning focused on the activities needed for start and successful launch of cooperation (analyses, agreements, negotiations...). This specialized managerial activity then ends.

- Planning in dynamic environment: Decline or significant change of a cooperation bond is a frequent occurrence. Planning then becomes specific to the situation such as successful termination of the cooperation (division of shares, settlements etc.) or a transformation in relation to the set goals.

Strategic planning relates to the start of cooperation and to setting parameters of its existence. The term "existence" here means that on the strategic level exact parameters of competitiveness of the cooperation bond are specified. If it happens that these cease to be achievable in a given situation, termination or modification of the cooperation follows. Tactical planning relates to specific cases of facilitating cooperation and its termination or transformation. Operational planning is used in the standard meaning as well as in the case of the mentioned specific cases.

Competitiveness and efficiency (power and reciprocity) are in general the long-term strategic goals of cooperation groups. In concrete cases - strategic goals adjusted to fit given situation. Other goals (tactical and operational) are managed by mutual agreement of the cooperating parties and are primarily dependent on the market situation.

\section{Efficient Organization of Cooperation Activities in a Company}

Organization, whether commercial or not, is a social group. Its goal is to fulfill the set goals. Cooperating organization have certain categories in common. Most often these are common goals that can be reached more effectively via cooperation. Organizations assume culture of the society from which they stem and at the same time they create their own (organizational or company culture). Success represents an important aspect this is represented in a way by company survival, market success, profit etc. If organization is not in the long-term successful in fulfilling its goals or it is not competitive, one of the solutions is to connect with other organization or organizations.

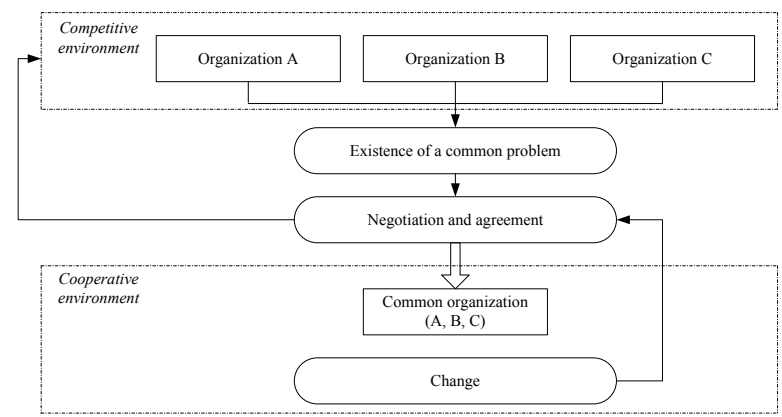

Fig. 2 Process of creating cooperation organization Source: [18]

Figure 2 represents basic steps necessary for creating cooperating organization. Organizations exist in a state of mutual competition. In case a certain problem turns out to be significant 
enough, it may represent a potential stimulus for establishing mutual cooperation. Mutual discussion and agreement leads to cooperation. Organizations exist in a dynamic environment that creates further changes that in turn create need for another discussion (planning and decision making). This may result in a decision to continue the cooperation, to modify it or to terminate it and to return to mutual competition.

The described aspects form dynamic cooperation organizational structures, that are created, modified and terminated, depending on current goals and tasks. One organization could participate in multiple dynamic organizational structures. It could also be the case that only a part of organization participates. This arrangement enables individual structures and employees to work on tasks from multiple projects, depending on the current needs. The cooperation organization itself takes on standard organizational structures.

Frequently we encounter matrix organizational structure, which suitably addresses the needs created by the environment dynamics. This type of organizational structure is also partially defined by the management literature: "Virtual organization or organization with virtual organizational structure is a special type of organization. It differs significantly from the hierarchical organizations. It is a temporary connection of companies, based on information technologies. Its purpose is to rapidly and efficiently use available entrepreneurial opportunities. Subjects connected within the virtual organization are not connected via ownership, and do not form formal organizational structures. Rather, they are independent and each of them contributes to taking advantages of the opportunity by its specific skill and obtains that what could not be obtained in being isolated" [19].

\section{Work with people in managing cooperative activities}

Within the context of cooperative activities, communication needs to be open, transparent and informal, enabling easy exchange of strategic information between internal and external parties.

In terms of personnel active in the management of cooperation activities, it would be preferable that one person would bear responsibility for the cooperation - a manager of cooperation.
Such person would be responsible for smooth progress of the cooperation activities. The following Table 3 lists requirements and job description of this work position.

Manager of cooperation should also take the leadership role. This means $\mathrm{s} /$ he needs to be able to set a vision of future company success and clearly define cooperative opportunities that will lead to achieving this success. $\mathrm{S} / \mathrm{he}$ needs to be able to transform this vision into cooperative programs and to win support of top management for their realization. $\mathrm{S} /$ he should be able to motivate her/his team members for realization of cooperative activities and to create effective cooperative team.

Related to the theme of leadership, it is suitable to strengthen motivation of employees by a company remuneration scheme. The process of employee motivation should mainly include basic needs of employees [20]. Company should particularly pay attention to defining of the evaluation, criteria based on which will the outcomes of cooperation activities be evaluated.

\section{Control in the management of cooperation activities}

In general, control is used to monitor the level of fulfilling of cooperation goals. It involves the process of tracking, analysis, evaluation, and making conclusions about the deviations between the goal (plan) and its realization. It is necessary to set control points within the process of realization of cooperation activities so that correct measures can be taken in case of deviations. Ideally, control should be performed after conclusion of every phase in the proposed model.

\section{Discussion}

The elementary prerequisite for successful functioning of the proposed model of management of cooperation activities is a detailed analysis of cooperation activities within the company. For this purpose a variety of analyses can be used (SWOT, SPACE, STEEP, PORTER, etc.) that will help to identify partial problems of a company in the field of realizing its cooperation activities.

In most cases, these analyses confirm weak utilization of cooperation opportunities in a company. Another problem is

Requirements and job description for the position manager of cooperation

\begin{tabular}{|l|l|}
\hline Requirements & Job description \\
\hline - Creativity & - Evaluate and process all real needs within cooperation \\
- Teamwork and communication & - Create cooperation team \\
- Managerial skills & - Coordinate tasks of the cooperation team \\
- Experience, track record & - Evaluate effects of the realized cooperation activity \\
& - Organization and chairing of the mutual meetings \\
& - Responsibility for cooperative ideas (record keeping, identification of the best ideas, \\
& prioritization, decision making) \\
\hline
\end{tabular}


insufficient utilization of cooperation potential, which results in low rate of utilization of already existing partnerships.

Another necessary prerequisite for success is a suitable information background for managing cooperation activities in a company. A system should be in place to ensure and enable suitable information background. It should also take into consideration the requirements of the people involved in the newly created cooperation.

Top management of the company should also support nurturing of creative human potential. This means that the employees should be able to fully utilize their skills and abilities during their work on cooperation activities. Specifically, during the first and second phase of the model presented above, a need for cooperation arises and cooperation ideas are created. In these stages employees apply their ability to identify opportunities, structure and plan changes and come up with ideas and solutions. In the consequent phases of the model employees need to apply their ability to realize cooperation activities, manage the cooperation process and to continuously learn based on the development of the cooperation. By practicing their ability to cooperate, employees can identify new sources of ideas, e.g. potential shared use of research and development facilities etc.

In order for the cooperation activities to be managed efficiently, it is necessary that the company demonstrates certain results in the areas that influence its management of cooperation. Every company has a different level of management of cooperation activities. It is therefore needed, as the first step, to ascertain the current level of management of cooperation activities in a company. This is followed by identification of weaknesses and by formulation of recommendations for improvement. For this to work, it is necessary to have in place a suitable methodology for evaluation of the management of cooperation activities in a company.

\section{Conclusions}

Ideas about complexity of managing cooperation activities in a company are justified. The topic of managing cooperation activities is currently very relevant among Slovak enterprises. Managers in Slovak enterprises strive to build cooperation management in their companies, aiming to enable creation of successful cooperation and fulfillment of set cooperation tasks. In order for this initiative to be successful, it is needed to use elements of project management and to establish such environment that will support new cooperation, enable communication and effective work with information within created partner relationships [21].

The general belief that managing cooperation activities in a company is a complex undertaking is indeed justified. The search for one effective concept of the management of cooperation activities that would be applicable to all companies is a strenuous task. This is because each company has at its disposal different amount of cooperation resources and each company realizes different types of cooperation on a different level. The proposed model aims to contribute to better clarity and understanding in this area of research.

\section{Acknowledgement}

This paper was partially supported by the Slovak scientific grant VEGA 1/0621/14 Marketing management in cooperative environment - Proposal of strategic cooperation management implementation model.

\section{References}

[1] RAY, P. K.: Cooperative Management of Enterprise Networks. Kluwer Academic Publishers, 2002.

[2] VALENZUELA, J. L. D., VILLACORTA, F. S.: The Relationship between the Companies and their Suppliers. J. of Business Ethics 22(3): 273-280, 1999.

[3] VEERAKUMARAN, G.: COCM 511 - Management of Cooperatives and Legal Systems, Faculty of Dryland Agriculture and Natural Resources: Mekelle University, 2006.

[4] ZHANG, W.: Cooperation System Constructing and Model of its Operation Mechanism, Proc. of the Intern. Conference on Business Management and Electronic Information (BMEI), vol. 3, 2011, 784-787, 2011.

[5] SOVIAR, J., VODAK, J.: Value Network as Part of New Trends in Communication. Communications - Scientific Letters of the University of Zilina, vol. 14, No. 2, 2012. ISSN 1335-4205.

[6] SAHUT, J.-M., PERIS-ORTIZ, M.: Small Business, Innovation, and Entrepreneurship. Small Business Economics, 42(4): 663-668, 2014.

[7] RITALA, P., SAINIO, L.M. Coopetition for Radical Innovation: Technology, Market and Business-model Perspectives. Technology Analysis \& Strategic Management 26(2): 155-169, 2014.

[8] MUTAK, M.: Service Innovation in Networks: A Systematic Review and Implications for Business-to-business Service Innovation Research. J. of Business \& Industrial Marketing 29(2): 151-163, 2014. 
[9] KULTTI, K.: Sellers like Clusters. J. of Theoretical Economics 11(1), 2011.

[10] FELZENSZTEIN, C., GIMMON, E., AQUEVEQUE, C.: Cluster or Un-clustered Industries? Where inter-firm marketing cooperation matters. J. of Business \& Industrial Marketing, 27(5): 392-402, 2012.

[11] WECK, M., IVANOVA, M.: The Importance of Cultural Adaptation for the Trust Development within Business Relationships. $J$. of Business \& Industrial Marketing 28(3): 210-220, 2013.

[12] WICKS, A. C., BERMAN, S. L., JONES, T. M.: The Structure of Optimal Trust: Moral and Strategic Implications. Academy of Management Review, 24(1): 99-116, 1999.

[13] FAWCETT, S. E., JONES S. L., FAWCETT A. M.: Supply Chain Trust: The Catalyst for Collaborative Innovation. Business Horizons, 55(2): 163-178, 2012.

[14] MONCZKA, R. M., PETERSEN, K. J., HANDFIELD, R. B., RAGATZ, G. L.: Success Factors in Strategic Supplier Alliances: The Buying Company Perspective. Decision Sciences, 29(3): 553-577, 1998.

[15] JASSAWALlA, A. R., SASHITTAL, H. C.: An Examination of Collaboration in High-Technology New Product Development Processes. J. of Product Innovation Management, 15(3): 237-254, 1998.

[16] SCHMOLTZI, C., WALLENBURG, C. M.: Operational Governance in Horizontal Cooperations of Logistics Service Providers: Performance Effects and the Moderating Role of Cooperation Complexity. J. of Supply Chain Management, 48(2): 53-74, 2012.

[17] ROBBINS, P. S., COULTER, M.: Management (in Czech), Grada : Praha. ISBN 80-247-0495-1, 2004.

[18] SOVIAR, J.: From Cooperation to Management - Cooperative Management (in Slovak). Habilitation thesis. University of Zilina: Faculty of Management Science and Informatics, 2012.

[19] VEBER, J. et al.: Management. Foundations, Prosperity, Globalization (in Czech), Management Press: Prague, 2006.

[20] KAMPF, R., HITKA, M., POTKANY, M.: Interannual Differences in Employee Motivation in Manufacturing Enterprises in Slovakia. Communications - Scientific Letters of the University of Zilina, vol. 16, No. 4, 2014, ISSN 1335-4205.

[21] VODAK, J., SOVIAR, J., LENDEL, V.: Identification of the Main Problems in Using Cooperative Management in Slovak Enterprises and the Proposal of Convenient Recommendations, Communications - Scientific Letters of the University of Zilina, 15(4): 63-67, 2013. 